\title{
Pulmonary effects of contact exposure to paraquat: a clinical and experimental study
}

\author{
P J LEVIN, L J KLAFF, A G ROSE, AND A D FERGUSON \\ From the Respiratory Clinic, Departments of Medicine and Anaesthetics, and the Department of \\ Pathology, Groote Schuur Hospital and the University of Cape Town, Observatory, Cape Town, \\ South Africa
}

ABSTRACT The clinical and pathological features of a patient who died from the effects of percutaneous absorption of paraquat are described. The toxin was absorbed during the spraying of vineyards. Nine of his co-workers, less heavily exposed, were investigated. The transfer factor for carbon monoxide was reduced in six. Lung biopsy of two showed medial hypertrophy of the pulmonary arteries with evidence of fresh and organised thrombi. In one there was also interstitial fibrosis. We designed an experimental animal model to investigate these findings. Low concentrations of paraquat were applied to the skin of rats over a nine-week period. The lungs were examined postmortem, and the medial thickness of the muscular pulmonary arteries was expressed as a percentage of their external diameters. In randomly encountered (large and small) pulmonary arteries the mean percentage medial thickness (MT\%) was $11.99 \pm 0.41 \%$ (SEM) in controls and $25.28 \pm 0.94 \%$ in test rats $(\mathrm{P}<0.001)$. In the large muscular pulmonary arteries the MT\% in the control rats was $13.6 \pm 0.49 \%$ and in the test rats $25.9 \pm 1.44 \%(\mathrm{P}<0.001)$. In the small pulmonary arteries the values were: controls $9 \cdot 0 \pm 0.73 \%$ and tests $14.2 \pm 1.35 \%$ $(P<0.05)$. One test rat which died spontaneously showed pulmonary infarction from thrombosis. We concluded that paraquat absorbed through the skin in low dosage over a prolonged period can produce pulmonary arterial lesions in man and rat. This contrasts with the familiar pathological findings of acute high dose ingestion. These findings have important bearings on the use of this herbicide in agriculture.

Paraquat $\left(1 \cdot 1^{\prime}\right.$-dimethyl-4,4'bipyridylium dichloride) is a herbicide extensively used throughout the world. Numerous fatal cases of paraquat poisoning have been reported as a result of accidental or suicidal swallowing of the compound (Malone et al, 1971; Eliahou et al, 1975; Fairshter et al, 1976; Klaff et al, 1977). The death rate from swallowing paraquat, even in small quantities, has been estimated as in the region of between 33 and $50 \%$ (Lancet, 1971). Absorption of the toxin by routes other than parenteral has not been considered to be of clinical importance (Fairshter and Wilson, 1975) until recently when Jaros (1978) reported a fatal case from skin exposure to a concentrated solution.

We present the case of a patient who was admitted to hospital with a clinical history and course consistent with paraquat poisoning. His only exposure to the herbicide had been while he was spraying vineyards. This case illustrates that fatal paraquat poisoning can occur by percutaneous absorption using the recommended concentration.

In view of the potential public health hazard to the farming community we investigated his fellow farm workers and also designed an experimental rat model to show whether skin absorption of small quantities of the toxin, insufficient to cause the well-described acute severe pathological changes, can cause pulmonary damage.

\section{Case 1}

A 29-year-old man was admitted complaining of severe dyspnoea. He had been perfectly well until just over two weeks before when he had been spraying the weeds between the dormant vines with Gramoxone (diluted to contain $2.8 \%$ paraquat). The patient had balanced the reservoir of the spray on his shoulder where it had leaked, 
causing a burn (figs 1 and 2), instead of holding it, as recommended, at arms' length. This apparatus for spraying paraquat has been used for the past three years on this farm and on each occasion he had taken part in the spraying. The patient and his relatives were closely questioned, and it was firmly established that he had not swallowed the toxin. Moreover, he denied any history of sore mouth or throat. Within a week of exposure he developed shortness of breath. His dyspnoea increased, and a chest radiograph showed a fine nodular pattern. He was thus admitted to a tuberculosis hospital but within three days was transferred to our hospital because of rapid deterioration on antituberculosis treatment and because repeated sputa were negative for acid-fast bacilli. $\mathrm{He}$ was extremely tachypnoeic and cyanosed. His pulse rate was $120 / \mathrm{min}$ and crackles were heard at both bases. His temperature was $37 \cdot 5^{\circ} \mathrm{C}$. There was no clubbing of his fingers. The ulcer on his shoulder was noted.

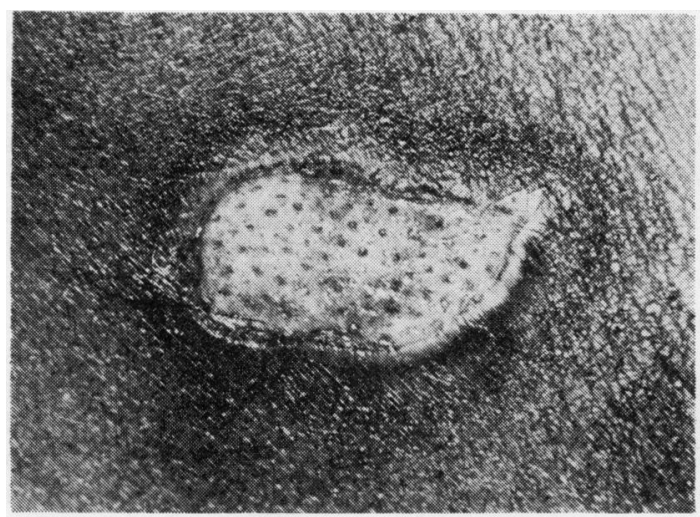

Fig 1 Appearance of skin ulcer on admission, three weeks after burn with paraquat.

\section{INVESTIGATIONS}

Investigations gave the following results: $\mathrm{Hb} \mathbf{1 2 \cdot 2}$ $\mathrm{g} / \mathrm{dl}$; white cell count $26 \times 10^{9} / 1(83 \%$ neutrophils); platelets $187 \times 10^{9} / 1$; Westergren ESR 90 $\mathrm{mm}$ in one hour; blood gases at rest: $\mathrm{Po}_{2} 5.9 \mathrm{kPa}$ (44 mmHg), $\mathrm{PCO}_{2} 4.9 \mathrm{kPa}(37 \mathrm{mmHg}) ; \mathrm{pH} \mathrm{7.36}$; chest radiograph: diffuse mottled opacification of both lung fields (fig 3); blood urea on admission: $35 \mathrm{mmol} / \mathrm{l}(215 \mathrm{mg} \%)$; creatinine $300 \mu \mathrm{mol} / 1$ (3.4 mg\%); AAT 127 (normal 10 to 50); bilirubin and alkaline phosphatase normal. No paraquat was detected in urine.

\section{TREATMENT AND PROGRESS}

Paraquat poisoning was diagnosed but a super-

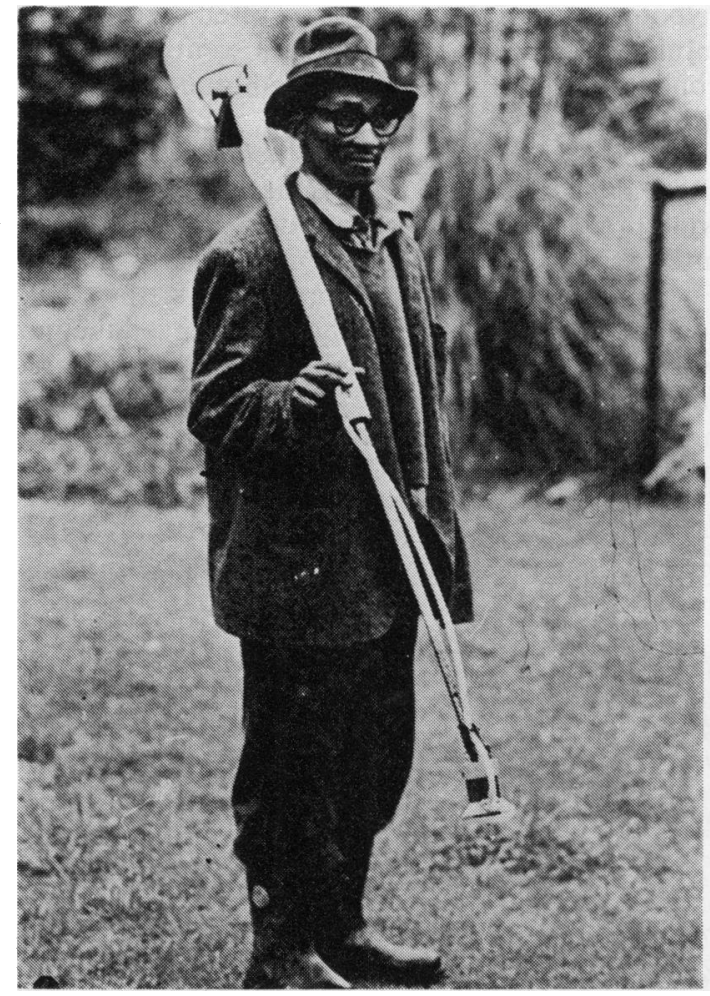

Fig 2 Farm labourer showing incorrect use of apparatus which led to shoulder burn.

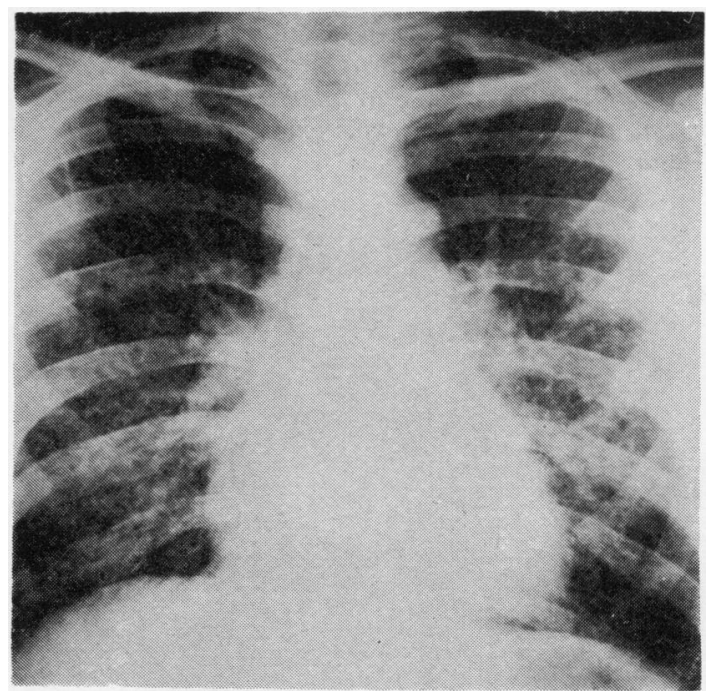

Fig 3 Patient 1. Chest radiograph on admission.

added infection could not be excluded. Antibiotics and steroids were given intravenously; oxygen was not administered but after three days he became 
hypotensive and shocked. He required nasotracheal intubation and positive-pressure ventilation. His condition, however, deteriorated rapidly, and he died of hypoxia three days later. At necropsy the changes in the lung were in keeping with acute paraquat poisoning. The lung architecture showed widespread focal disorganisation (fig 4 ) due to interstitial cellular infiltration and early fibrosis. Focal intra-alveolar haemorrhage together with squamous metaplasia of bronchiolar epithelium were also seen. The pulmonary arteries appeared intrinsically normal, but several arterioles appeared muscularised (fig 5). The pulmonary veins appeared normal.

\section{CLINICAL SURVEY}

Our patient was one of 10 farm workers who had

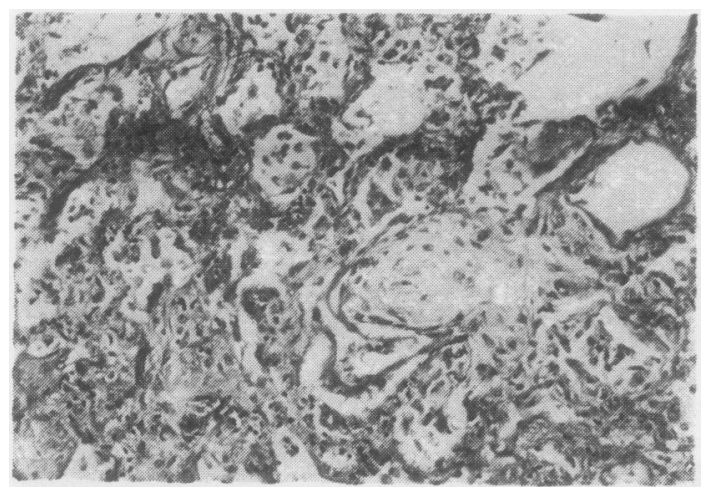

Fig 4 Patient 1. Lung histology. Lung architecture appears disorganised due to interstitial fibrosis and organisation of intra-alveolar exudate (Elastic van Gieson $\times 150)$.

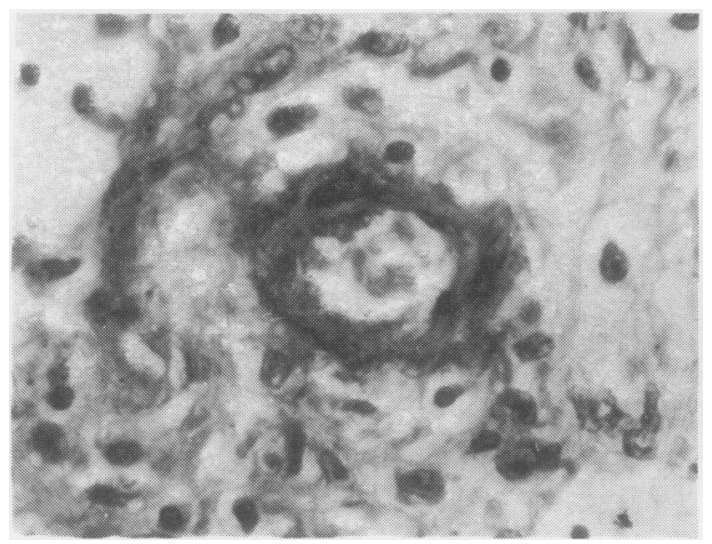

Fig 5 Patient 1. Lung histology showing muscularised arteriole surrounded by cellular exudate (Elastic van Gieson $\times 600$ ). taken part in the spraying of the vineyards during the winter. Five had been exposed to paraquat for that spraying season only; the other four had previously used paraquat for between two and four seasons. Over the past three years spraying had been performed using micron ultra low volume sprayers, which consist in essence of an atomiser head that spins at 1800 revolutions a minute and delivers particle sizes varying between 280 and $300 \mu \mathrm{m}$ in a circle with a diameter of $1.2 \mathrm{~m}$. The strength of solution used was $2.8 \%$ paraquat in a water-oil base. About 4001 of the solution is sprayed in the course of one day by one man, and any worker may spray up to 10 days a season. At no time had any worker worn protective clothing. In particular, the trousers below the knee were always soaked in the spray, and they complained of red, burning legs. Several had handled the concentrated solution.

The nine workers were questioned, particularly as to respiratory symptoms, and examined. Their ages varied from 16 to 34 years. They were all smokers. Only one patient admitted to mild dyspnoea and two had chronic cough and sputum production. Physical examination was normal in all cases. Chest radiography, urine examination, full blood counts, and grouped chemical analysis were done. Lung volumes, transfer factor for carbon monoxide, and blood gases at rest were measured. The urine was examined for paraquat by the dithionite test. Clinical details and pulmonary function test results are given in the table.

Our attention was drawn to two individuals (cases 2 and 3 ), both of whom had low gas transfer measurements coupled with reduced arterial oxygen pressures at rest. They were also the two men who had had the longest exposure. Open lung biopsy was performed on these two patients to determine the pathological basis for these abnormalities. Both patients gave informed consent.

\section{Case 2}

This 22-year-old man had sprayed the previous three seasons. He smoked a pipe and had bronchitic symptoms. His effort tolerance was normal, and he gave no history of dysponea at the time of spraying. Results of physical examination were normal.

INVESTIGATIONS

Investigations gave the following results: Hb $13.3 \mathrm{~g} / \mathrm{dl}$; white cell count $9.4 \times 10^{9} / 1$; normal differential count; Westergren ESR $23 \mathrm{~mm}$ in one hour; electrocardiograph: normal; chest radio- 


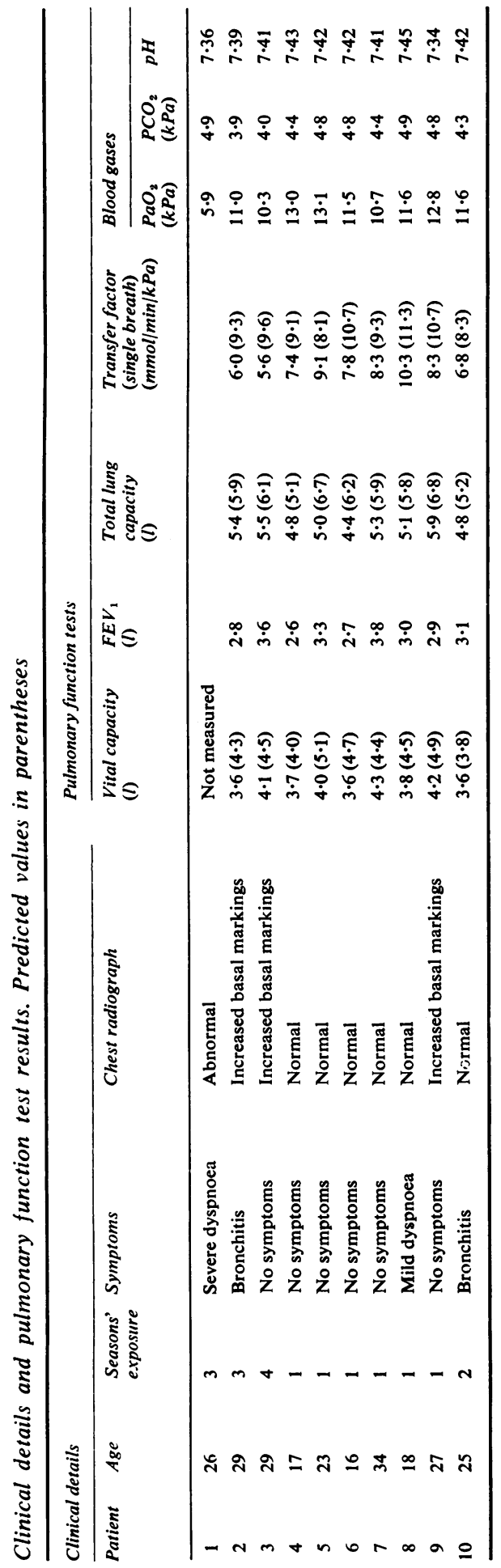


graph: minimal increase in basal markings; total protein $8 \mathrm{~g} / \mathrm{dl}$; albumin $3.5 \mathrm{~g} / \mathrm{dl}$; urea $3.5 \mathrm{mmol} / 1$ (22 $\mathrm{mg} \%$ ); immunoglobulins: IgG 238 international units/ml, IgA 427, and IgM 196; sheep cell agglutination: positive $1: 16$; latex agglutination test titre: positive $1: 320$; antinuclear factor: negative; serum complement: within normal range; LE cells: negative. For lung function tests see table.

The biopsy showed atelectatic lung with focal areas of interstitial fibrosis and cuboidal metaplasia of alveolar lining cells (fig 6). The pulmonary arteries showed medial hypertrophy (fig 7), and several arteries less than $300 \mu$ in diameter showed mild to moderate intimal fibroelastic thickening. An $800 \mu$ diameter pulmonary artery showed eccentric intimal thickening from organised thrombus (fig 8). The pulmonary veins appeared normal.

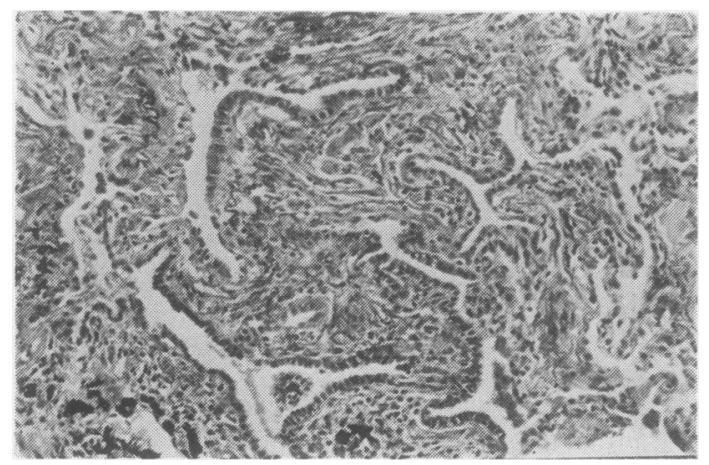

Fig 6 Patient 2. Lung biopsy showing an area of lung with interstitial fibrous thickening and cuboidal metaplasia of alveolar lining cells. Elsewhere lung appeared normal (Elastic van Gieson $\times 150)$.

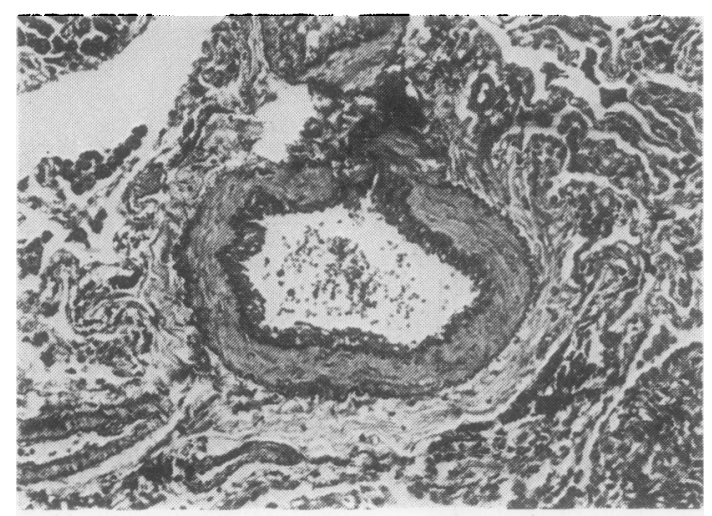

Fig 7 Patient 2. Lung biopsy: a $300 \mu$ diameter pulmonary artery showing moderate medial hypertrophy (Elastic van Gieson $\times 150$ ).

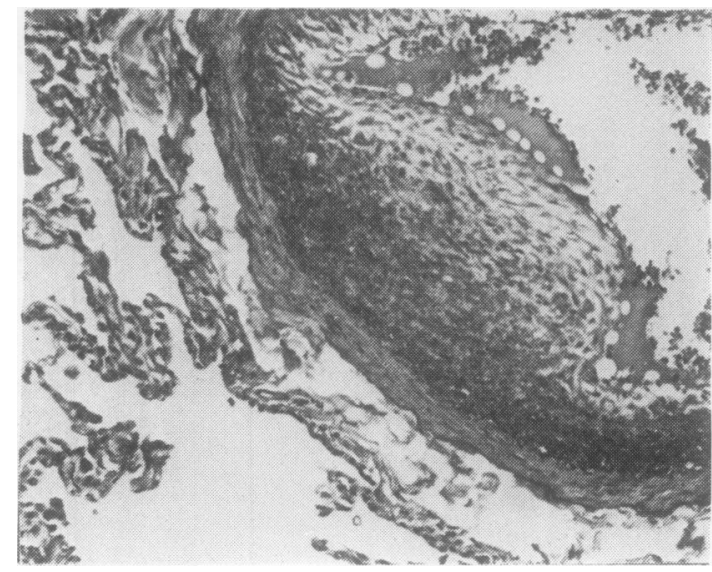

Fig 8 Patient 2. Lung biopsy: portion of an $800 \mu$ diameter pulmonary artery showing eccentric intimal thickening suggestive of organised thrombus (Elastic van Gieson $\times 150$ ).

\section{Case 3}

A 29-year-old man who had worked on the farm for three years had last been exposed to paraquat one month before admission. He smoked 20 cigarettes a day but had no respiratory symptoms. Results of physical examination were normal.

\section{INVESTIGATIONS}

Investigations gave the following results: urine: normal-no paraquat detected; $\mathrm{Hb} 16.5 \mathrm{~g} / \mathrm{dl}$; white cell count $7.9 \times 10^{9} / 1$; normal differential count; Westergren ESR $10 \mathrm{~mm}$ in one hour; electrocardiograph: normal; chest radiograph: normal. Grouped chemical analysis, protein electrophoresis, immunoglobulins, and serum complement were all within normal limits. Rheumatoid factor, antinuclear factor, and LE cells were negative. Lung function tests are shown in the table.

The biopsy showed numerous muscular pulmonary arteries with organising thrombi in their lumens (fig 9). There was evidence of mild medial hypertrophy in several of the pulmonary arteries. The lung tissue appeared normal. A few pulmonary arteries showed healed recanalised thrombi (fig 10), which clearly antedated the fresh thrombi.

\section{Experimental study}

The obvious question to be asked was whether these abnormal and unexpected findings in the pulmonary vessels of these two young men could be ascribed to paraquat. With this in mind we 


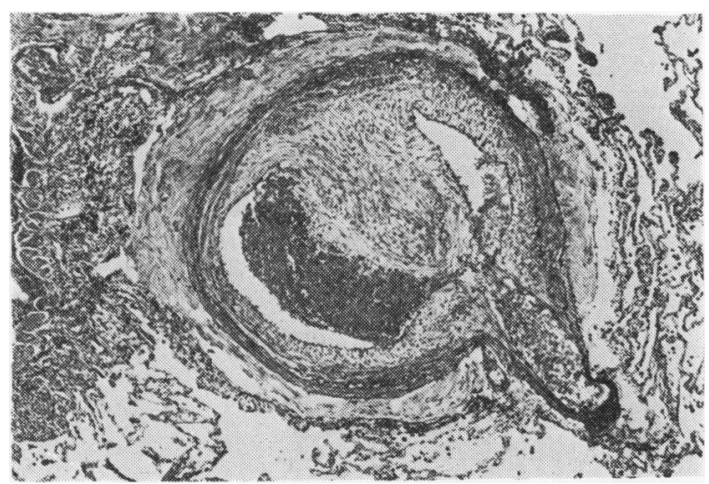

Fig 9 Patient 3. Lung biopsy showing muscular pulmonary artery containing recent organising thrombus (Elastic van Gieson $\times 30$ ).

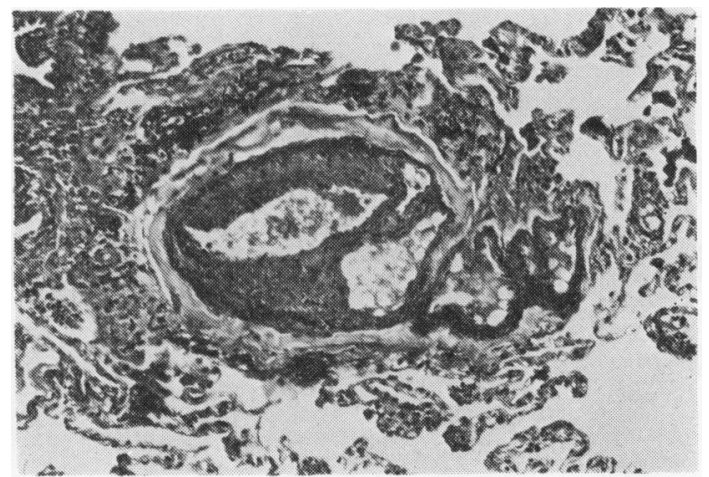

Fig 10 Patient 3. Lung biopsy showing old recanalised thrombus in pulmonary artery (Elastic van Gieson $\times 60)$. designed an experimental model for chronic cutaneous exposure to paraquat.

\section{METHODS}

Male Long Evans rats weighing about $250 \mathrm{~g}$ were used. An area of skin on the back of the neck was shaved weekly for application of paraquat. This site was selected as rats are unable to lick this area. The animals were divided into two groups.

Experimental group (18 rats) painted with a solution containing paraquat. Initially $1 \mathrm{ml}$ of solution containing $8 \mathrm{mg}$ of paraquat was applied at weekly intervals.

Contral group (seven rats) had only the skin shaved.

From the fourth week onwards two rats in the experimental group were killed at weekly intervals. One control rat was killed weekly from the fifth week onwards (fig 11-13). After six weeks, as the animals were tolerating the low concentration of paraquat well, the dose was increased to $28.5 \mathrm{mg} / \mathrm{ml}$. This is the same concentration as that sprayed in the vineyards. After four such exposures, two animals died spontaneously. Paraquat was not applied after the ninth week.

The lungs, kidneys, liver, and affected skin were removed, fixed in $10 \%$ buffered formalin, and processed by embedding in paraffin in the routine manner. Sections were stained with haematoxylin and eosin and by the Van Gieson-Verhoeff methods. The pulmonary arteries were examined morphometrically. The medial thickness of the first 16 muscular arteries encountered randomly microscopically in each animal were measured and expressed as a percentage of their external

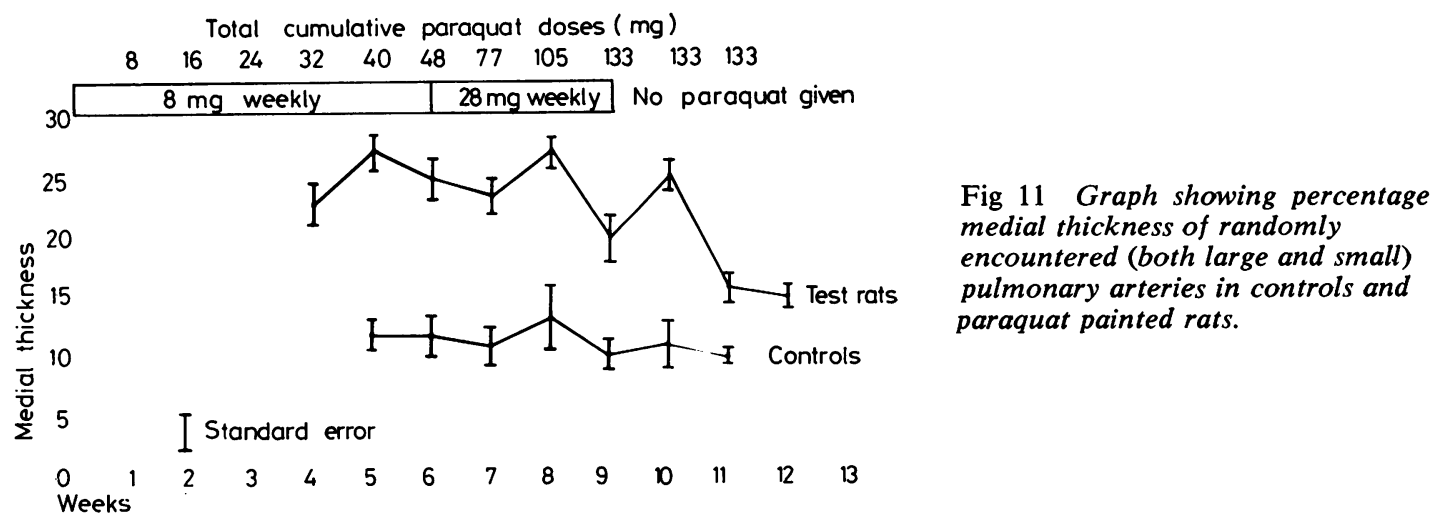

Fig 11 Graph showing percentage medial thickness of randomly encountered (both large and small) pulmonary arteries in controls and paraquat painted rats. 


\begin{tabular}{|c|c|c|c|c|c|c|c|c|c|c|}
\hline & \multicolumn{4}{|c|}{ Total cumulative } & \multicolumn{4}{|c|}{ paraquat doses $(\mathrm{mg})$} & \multirow{2}{*}{\multicolumn{2}{|c|}{133}} \\
\hline & 8 & 16 & 24 & 32 & 40 & 48 & 77 & 105 & & \\
\hline 30 & & $8 \mathrm{~m}$ & & ekly & & & $28 \mathrm{mg}$ & weekly & & paraquat given \\
\hline
\end{tabular}

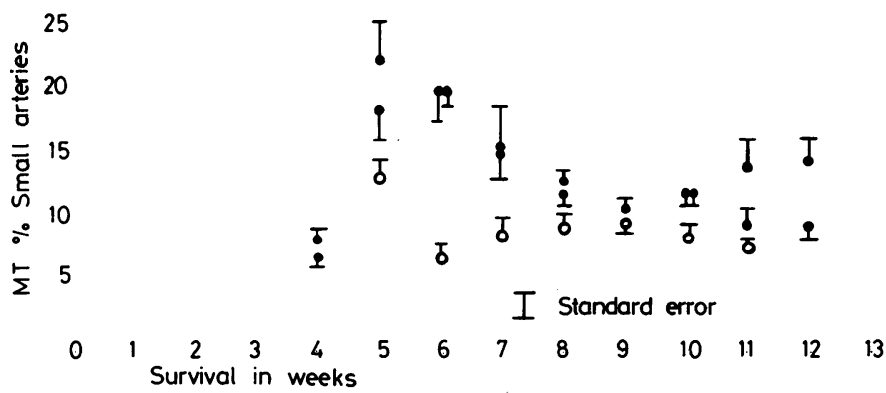

Fig 12 Graph showing percentage medial thickness of large thick-walled pulmonary arteries related to survival in weeks in test and control rats. In this graph and in fig 13 test rats are indicated by closed circles and control rats by open circles.

Total cumulative paraquat doses $(\mathrm{mg})$

$\begin{array}{llllllllll}8 & 16 & 24 & 32 & 40 & 48 & 77 & 105 & 133 & \text { B3 }\end{array}$

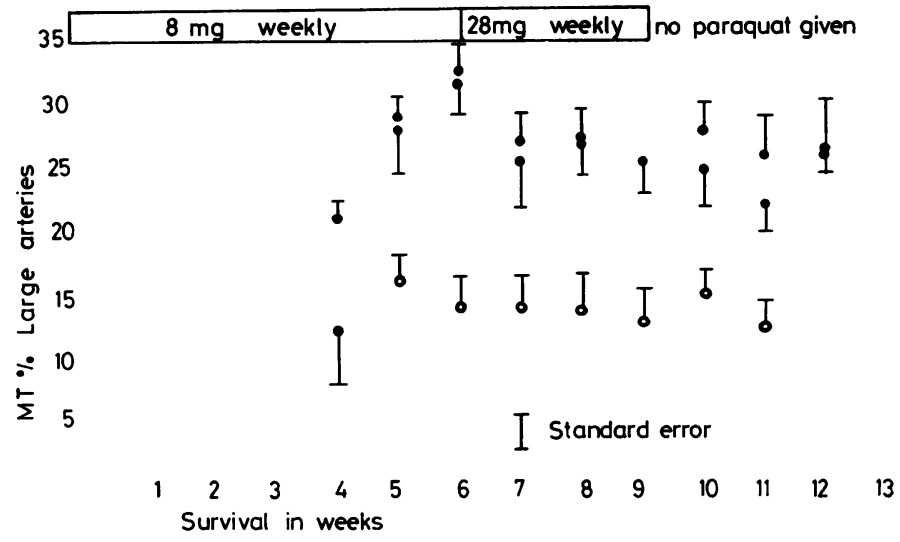

Fig 13 Percentage medial thickness of small thin-walled pulmonary arteries related to survival in weeks in test and control rats.

diameters (Wagenvoort et al, 1974). Since Smith and colleagues (1974a) have drawn attention to the fact that thick-walled large pulmonary arteries are normal in rats and should not be misinterpreted as evidence of hypertensive pulmonary vascular disease in test animals, the measurements were repeated using the following arbitrary division of pulmonary arteries.

In each animal we measured the medial thickness of eight large pulmonary arteries (diameters about $100-300 \mu \mathrm{m}$ ) and of eight small pulmonary arteries (diameters about $100 \mu \mathrm{m}$ ). Measurements were made on vessels that had been transversely sectioned. The single medial thickness was again expressed as a percentage of the external diameter of the vessel. A mean percentage for the arterial medial thickness in these two orders of pulmonary arteries was obtained in each rat. Alveolar capillaries were examined by electron microscopy in three test rats and three control rats.

\section{Results}

CONTROL RATS

The mean medial thickness of the randomly en- $N$ countered pulmonary arteries (large and small 0 arteries, fig 11) was $11.9 \pm 0.41 \%$ (SEM). The large pulmonary arteries (figs 12,14 ) had a medial $\frac{\mathbb{\Phi}}{\Phi}$ thickness of between 6.4 and $30.5 \%$ of their $\stackrel{?}{?}$ external diameter. The mean value for the medial 0 thickness was $13 \cdot 6 \pm 0 \cdot 49 \%$ (SEM).

The smaller thin-walled pulmonary arteries (figs 13,15 ) had a medial thickness ranging from $\mathbb{D}$ 3.4 to $20.0 \%$ of their external diameter; the mean value was $9 \cdot 0 \pm 0.73 \%$ (SEM).

The lungs of the control animals were free of 8 recent or old haemorrhage. The pulmonary veins 


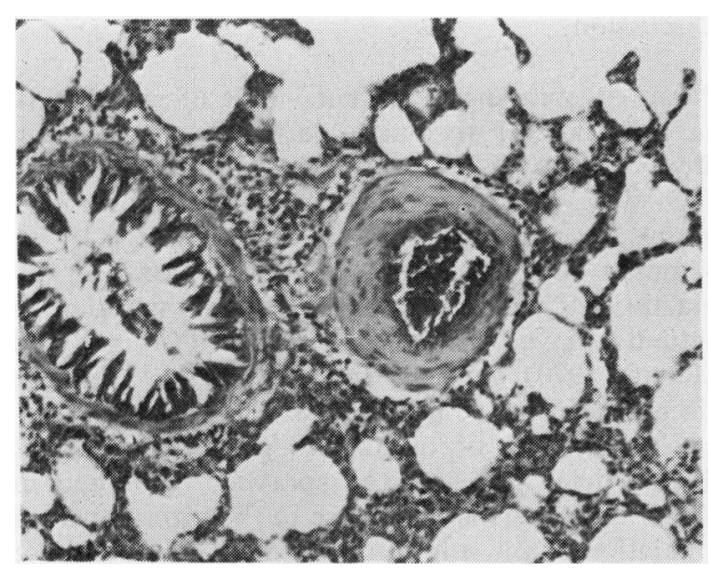

Fig 14 Large muscular pulmonary artery of control rat shows mild constriction and normal prominence of medial muscle (Elastic van Gieson $\times 60$ ).

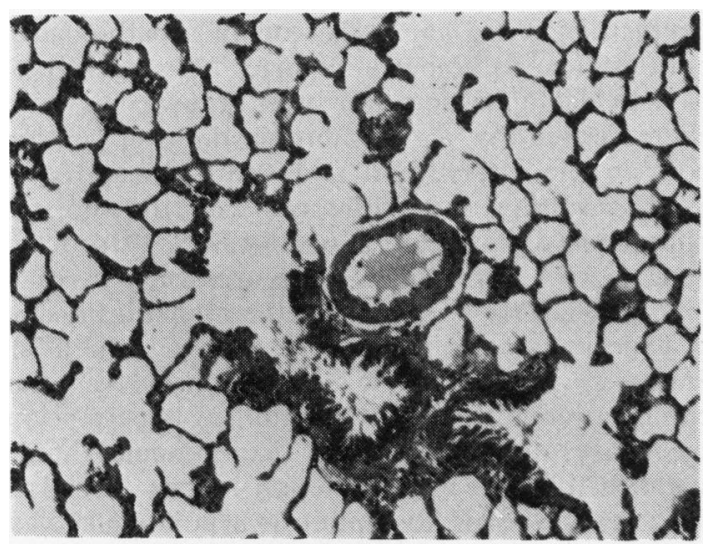

Fig 15 Histology of normal thin-walled muscular pulmonary artery of control rat showing thin media (Elastic van Gieson $\times 60$ ).

appeared normal, and no abnormality was detected in the livers or kidneys. Electron microscopy showed normal alveolar capillaries.

TEST RATS-qualitative changes

Foci of recent intra-alveolar haemorrhage were seen in the lungs of nine test rats. Three rats also had small foci of haemosiderin in the lung suggesting previous haemorrhage.

Only one of the two test rats that died spontaneously had a necropsy; the other was too autolysed. This rat's lungs showed foci of infarction and sub-infarction, and there were several occlusive thrombi in muscular pulmonary arteries (fig 16). Pulmonary veins were normal.

The painted areas of skin showed epidermal necrosis and ulceration with polymorphonuclear

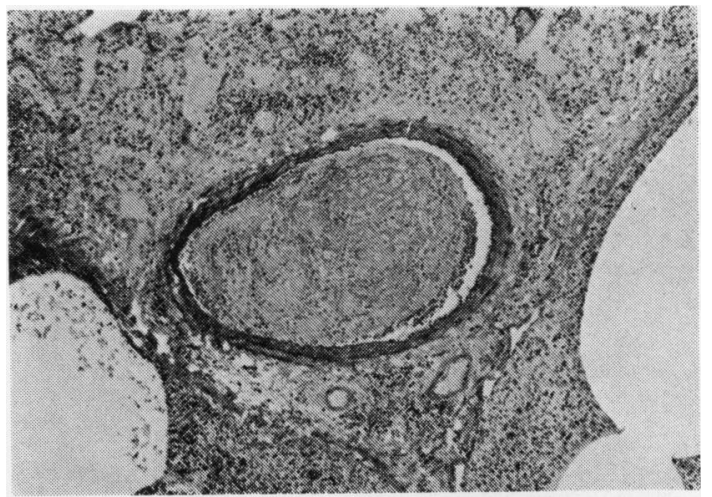

Fig 16 Unorganised thrombus occludes pulmonary artery in test rat that died spontaneously. Surrounding lung shows infarction (Haematoxylin and eosin $\times 60$ ).

leucocytes within the surface crust and chronic inflammatory cells in the dermis. The livers and kidneys appeared normal. Electron microscopy of pulmonary alveolar capillaries showed no abnormality.

\section{TEST RATS-quantitative results}

The mean medial thickness of randomly encountered large and small arteries (fig 11) in test rats was $25 \cdot 28 \pm 0.94 \%$. This was significantly greater than in the controls $(\mathrm{P}<0 \cdot 001)$.

\section{MEDIAL THICKNESS OF THE LARGE PULMONARY} ARTERIES

The mean percentage medial thickness of the large pulmonary arteries (figs $12,17,18$ ) in the control rats was $13.6 \pm 0.49 \%$ (SEM) and in the test rats it was $25 \cdot 9 \pm 1.44 \%($ SEM $)(\mathrm{P}<0.001)$.

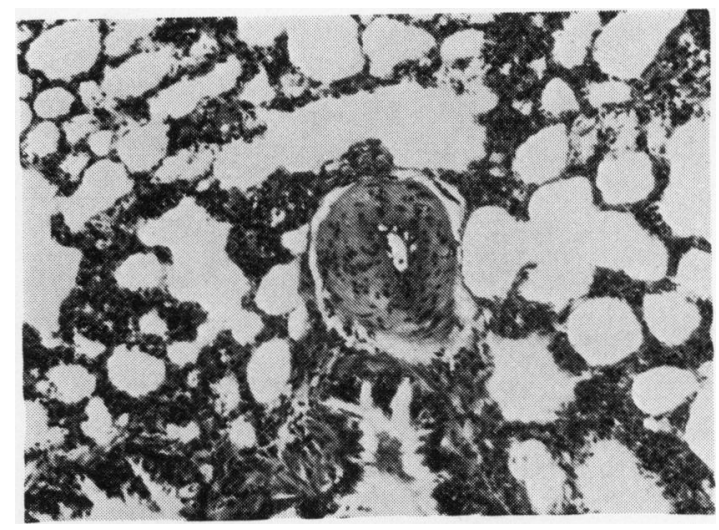

Fig 17 Constricted muscular pulmonary artery of test rat after five weeks' cutaneous application of paraquat (Elastic van Gieson $\times 60$ ). 


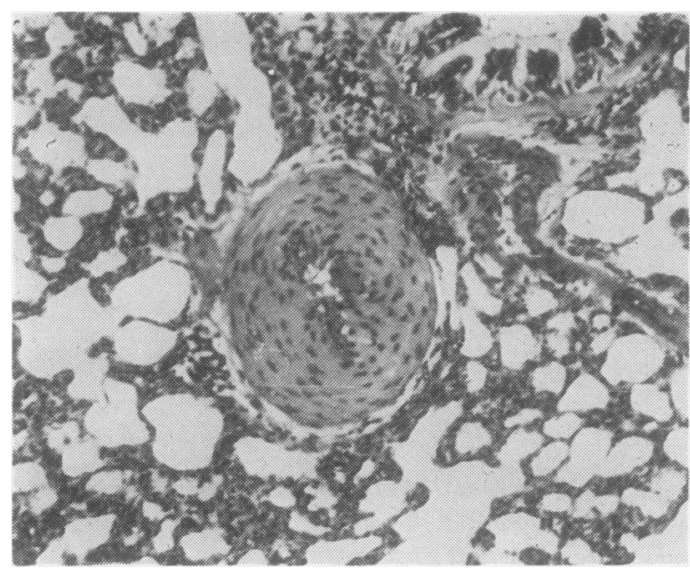

Fig 18 Large muscular pulmonary artery of test rat after six weeks' cutaneous application of paraquat shows severe vasoconstriction and thick medial muscle coat (Elastic van Gieson $\times 60$ ).

The percentage medial thickness of the large pulmonary arteries is plotted against survival period (fig 12). These arteries appeared to show more vasoconstriction than those in the controls and medial hypertrophy probably contributed to the increased percentage medial thickness.

\section{MEDIAL THICKNESS OF THE SMALL PULMONARY} ARTERIES

The percentage medial thickness of the small pulmonary arteries is plotted against length of survival (fig 13). The mean percentage medial thickness of the small pulmonary arteries in the test rats (fig 19) was $14 \cdot 2 \pm 1 \cdot 35 \%$ (SEM) and in the controls it was $9.0 \pm 0.73 \%(\mathrm{SEM})(\mathrm{P}<0.05)$.

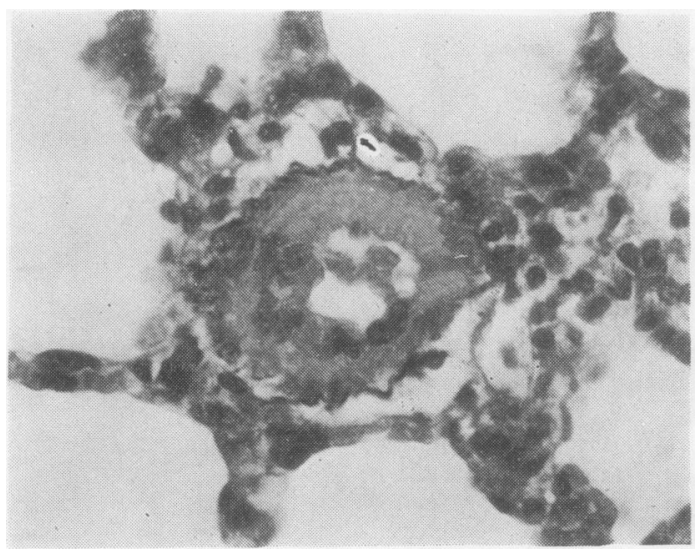

Fig 19 Muscularised arteriole in test rat after seven weeks' cutaneous application of paraquat (Elastic van Gieson $\times 300$ ).

\section{Discussion}

Paraquat spraying represents a significant health hazard and our recommendation for workers in the local vineyards to wear protective clothing has been widely adopted. Some effects of contact exposure have been described (Cant and Lewis, 1968; Samman and Johnston, 1969; McDonagh and Martin, 1970). Skin lesions similar to that in patient 1 have been noted before (McDonagh and Martin, 1970) but only in one instance has lung disease occurred (Jaros, 1978).

The addition of oil to the paraquat solution, the particle size, and the spraying technique in which the nozzle is kept close to the ground makes inhalation of the solution most unlikely. In patient 1 we were concerned as to the route of entry of the toxin. We were satisfied that he had not swallowed it.

Acute high dose ingestion and chronic low dose contact exposure cause two distinct pathological entities. The pathological changes from accidental or suicidal ingestion are well known and are characterised by active fibroblastic proliferation both in the interstitium and within the alveolar walls resulting in obliteration of the normal pulmonary architecture (Copland et al, 1974; Klaff et al, 1977). Vascular lesions are usually not a feature but have been described both clinically and in experimental animals (Smith and Heath, 1974; Smith et al, 1974b). The pulmonary vascular changes were attributed to pulmonary hypertension secondary to hypoxia. Our experimental study suggests that the primary lesion in rats from low dose percutaneous absorption is a pulmonary vascular abnormality with the acinar structures unaffected, though patient 1 , who died from massive skin absorption, showed the acute typical pulmonary acinar lesions. Some muscularisation of arterioles was, however, noted in addition. Of the two workers who had lung biopsies, patient 3 showed only vascular lesions; patient 2 showed both acinar and vascular lesions. Neither was significantly hypoxaemic (see table).

The lesions in the workers and the animals were not identical. Evidence of medial thickening was present in both but it was more extensive and uniform in the rats. Vascular thromboses were shown in both groups but were more obvious in $\stackrel{9}{\rightarrow}$ the workers. Cutaneous administration of paraquat to rats was associated with intra-alveolar haemorrhage and an increase in percentage med'al thickness of both large and small pulmonary arteries compared with controls. Muscularisation of pulmonary arterioles was also observed in test rats. Normal rats may have thick-walled large 
pulmonary arteries (Smith et al, 1974a). While the mean medial thickness of our control rats' large pulmonary arteries $(13.6 \%)$ approximates that reported by the latter authors $(15.9 \%)$, our test rat values were far higher $(25.9 \%)$. It is difficult to assess how much of the medial increase is due to vasoconstriction and how much is due to hypertrophy.

All the farm workers studied were either Africans or of mixed origin, and all had lung volumes below predicted values. Since our normal values are derived from a Caucasian population (Cotes, 1975), who are known to have higher vital capacities than other races (Johannsen and Erasmus, 1968), this might not represent a true abnormality. The single breath diffusing capacity was reduced in six out of nine people tested and was particularly low in the two selected for lung biopsy. Both had similar lung arterial lesions, which may have accounted for this. In addition, patient 2 had definite interstitial and intra-alveolar abnormalities. The pathogenesis of these changes is not clear. Certainly there is the possibility that this may represent a response to paraquat. However, we cannot exclude other incidental coexisting causes for this fibrosis. The significance of the positive rheumatoid factor in this patient is uncertain. A high frequency of positive rheumatoid factor has been described in several fibrotic lung diseases including asbestosis (Turner-Warwick, 1973) and cryptogenic fibrosis (Turner-Warwick, 1971-72). As there is no evidence at present of rheumatoid disease in our patient we assume that these serological abnormalities are also immunological reactions to his fibrosis.

In patients 2 and 3 there was no clinical or ECG evidence of pulmonary hypertension or any evidence of peripheral venous thrombosis. It would thus seem that the thromboses in the pulmonary vessels are secondary to arterial wall changes induced by the paraquat. In support of this it is interesting that the one test rat (B11), which died spontaneously, had extensive intrapulmonary thromboses as well as medial hypertrophy.

Paraquat is not the first toxin known to induce pulmonary arterial changes in animals. Two pyrrolizidine alkaloids, monocrotaline (Lalich and Merkow, 1961) and fulvine (Wagenvoort et al, 1974) both contained in Jamaican bush tea, cause arterial lesions in rats. Bush tea toxicity causes hepatic venous thrombosis in man (veno-occlusive disease) (Bras and McLean, 1963), but the pulmonary arteries are not affected. In 1972 considerable interest was aroused by an epidemic of pulmonary hypertension occurring in Germany,
Austria, and Switzerland in association with the taking of an appetite suppressant drug, aminorex (Kay et al, 1971). In this instance it has not been possible to reproduce these lesions in animals. It would appear therefore that paraquat is the first substance incriminated as a cause of pulmonary arterial changes in man which will produce similar lesions in animals.

There is good pathological evidence that the early lesions of medial hypertrophy in pulmonary hypertension are reversible (Wagenvoort and Wagenvoort, 1977). Withdrawal of exposure to paraquat may possibly lead to regression of hypertrophy. Paraquat is used in the vineyards only once a year when the vines are dormant. Our patients had lung biopsies a month after their last exposure. We may not therefore have shown the lesions at their most florid period. Between seasons the lesions may regress completely. The only interval evidence of the vascular damage would then be the organised thrombi where these had formed on damaged vessels. This may explain why clinical pulmonary hypertension has not been shown in these workers.

The practical importance of these studies is the demonstration that the routine use of paraquat can cause potentially severe pulmonary vascular disease. Paraquat cannot therefore any longer be regarded as a dangerous toxin only when swallowed either accidentally or with suicidal intent.

\section{References}

Bras, G, and McLean, E (1963). Toxic factors in veno-occlusive disease. Annals of the New York Academy of Science, 111, 392-398.

Cant, J S, and Lewis, D R H (1968). Ocular damage due to paraquat and diquat. British Medical Journal, 2, 224.

Copland, G M, Kolin, A, and Schulman, H S (1974). Fatal pulmonary intra-alveolar fibrosis after paraquat ingestion. New England Journal of Medicine, 291, 290-292.

Cotes, J E (1975). Lung function: Assessment and A pplication in Medicine, 3rd edn. Blackwell, Oxford.

Eliahou, H E, Almog, C, Gura, V, and Iaina, A (1975). Treatment of paraquat poisoning by hemodialysis. Israel Journal of Medical Sciences, 9, 459-462.

Fairshter, R D, Rosen, S M, Smith, W R, Glauser, F L, McRae, D M, and Wilson, A F (1976). Paraquat poisoning: New aspects of therapy. Quarterly Journal of Medicine, New Series, 45, 551-565.

Fairshter, R D, and Wilson, A F (1975). Paraquat poisoning; manifestations and therapy. American Journal of Medicine, 59, 751-753.

Jaros, F (1978). Acute percutaneous paraquat poisoning. Lancet, 1, 275. 
Johannsen, Z M, and Erasmus, L D (1968). Clinical spirometry in normal Bantu. American Review of Respiratory Disease, 97, 585-597.

Kay, J M, Smith, P, and Heath, D (1971). Aminorex and the pulmonary circulation. Thorax, 26, 262-270.

Klaff, L J, Levin, P J, Potgieter, P D, Losman, J G, Nochomovitz, L E, and Ferguson, A D (1977). Treatment of paraquat poisoning with the membrane oxygenator: a case report. South African Medical Journal, 51, 203-205.

Lalich, J J, and Merkow, L (1961). Pulmonary arteritis produced in rats by feeding Crotalaria spectabalis. Laboratory Investigation, 10, 744-750.

Lancet (1971). Paraquat poisoning. 2, 1018-1019.

McDonagh, B J, and Martin, J (1970). Paraquat poisoning in children. Archives of Disease in Childhood, 45, 425-427.

Malone, J D G, Carmody, M, Keogh, B, and O'Dwyer, W F (1971). Paraquat poisoning; a review of nineteen cases. Journal of the Irish Medical Association, 64, 59-68.

Samman, P D, and Johnston, E N M (1969). Nail damage associated with handling of paraquat and diquat. British Medical Journal, 1, 818-819.

Smith, P, and Heath, D (1974). Paraquat lung: A reappraisal. Thorax, 29, 643-653.
Smith, P, Heath, D, and Hasleton, P (1974a). Effects of prolonged administration of chlorphentermine on the rat lung. Pathologia Europaea, 9, 273-287.

Smith, P, Heath, D, and Kay, J M (1974b). The pathogenesis and structure of paraquat-induced fibrosis in rats. Journal of Pathology, 114, 57-67.

Turner-Warwick, M (1971-72). Cryptogenic fibrosing alveolitis. British Journal of Hospital Medicine, 7, 697-704.

Turner-Warwick, M (1973). Immunological mechanisms in occupational disorders. Proceedings of the Royal Society of Medicine, 60, 927-930.

Wagenvoort, C A, and Wagenvoort, N (1977). Pathology of Pulmonary Hypertension. John Wiley, New York.

Wagenvoort, C A, Wagenvoort, $\mathbf{N}$, and Dijk, H J (1974). Effect of fulvine on pulmonary arteries and veins of the rat. Thorax, 29, 522-529.

Requests for reprints to: A D Ferguson, Respiratory Clinic, Department of Medicine, Groote Schuur Hospital and University of Cape Town, Observatory, Cape Town, 7925. 